\title{
Trust motivation: The self-regulatory processes underlying trust decisions
}

In recent decades, research has revealed undisputable evidence that trust is an essential ingredient for the functioning of effective interpersonal relationships providing a social lubricant to foster cooperation and mutually beneficial exchange. It is no surprise then that in organizational settings where individuals must work interdependently to achieve their goals, trust has been shown to be vital to success at individual and organizational levels (Colquitt, Scott, \& LePine, 2007). Trust is most often portrayed as a willingness to be vulnerable to the behaviors and decisions of others (Mayer, Davis, \& Schoorman, 1995). This sense of willingness emerges from a cognitive process that discriminates trustworthy from less trustworthy individuals (Lewis \& Weigert, 1985). According to such rational choice models, the decision to trust someone is seen as a rather straightforward function of the characteristics of the trustee and the trustor's disposition to shape perception in a certain way, also referred to as trust propensity (e.g., Mayer et al., 1995).

A preoccupation with interpersonal trustworthiness perceptions as the primary antecedent of trust (Baer \& Colquitt, 2018), has meant that one important aspect is conspicuously absent in existing trust models: the dynamic, intra-individual processes unfolding during trusting. Specifically, we argue that people's willingness to be vulnerable towards others constitutes an aspect at the heart of the definition of trust that has remained unexplored. Conceptualizing willingness as a volitional act necessitates a consideration of motivation as a potentially important intra-individual process driving the decision to trust. In support of our efforts, a recent volume (Searle, Nienaber, \& Sitkin, 2018) noted that the trust literature so far is suffering from a relative lack of process focused theorising and empirical work on ongoing trusting (see also Lewicki, Tomlinson, \& Gillespie, 2006). 
With the exception of a handful of authors (e.g., Weber, Malhotra, \& Murnighan, 2004; Williams, 2001) motivational processes have been largely overlooked within the organizational trust literature. However outside of the organizational sciences, the motive to trust has been identified as a fundamental need that influences cognitive processes (Fiske, 2004) such as those identified in traditional trust models (Mayer et al., 1995). Moreover, being motivated to trust others is important because it facilitates the fulfillment of other needs ultimately contributing to evolutionary success (Simon, 1990), at individual and organizational levels (Fukuyama, 1995). It is thus clear that motivation is likely to be involved in the initiation of trust and its development over time and offers a wealth of opportunities for developing a broader and more in depth understanding of trust decisions.

Of course, we are not saying that trustworthiness perceptions are not important or even necessary, but we argue that reasons exist why people cognitively analyze social information and many of those reasons are likely to be motivational. In essence, we perceive, expect and analyze social relationships at a cognitive level because of the motives that drive us in the first place (Kunda, 1990; Lemay \& Clark, 2015). Furthermore, motivation undoubtedly determines how willing people are to continue established relationships and maintain trust levels or even restore trust breaches. In order to achieve a more comprehensive understanding of the drivers, persistence and direction of a willingness to be vulnerable, it is critical that we focus on the influence of intra-individual motivational trust processes, in combination with variables identified in traditional trust models. In particular, a motivated approach is best placed to analyze the trust volition processes highlighted by the use of the term willingness in commonly used trust definitions.

Our model proposes a process of trust motivation and volition which describes both why individuals are motivated to trust specific other parties and how trust as a willingness to be vulnerable, is regulated over time. We define trust motivation as an intra-individual 
psychological state that represents a desire to be vulnerable to another in order to build or maintain a trusting relationship. As a consequence, a trustor is motivated to attain a certain level of trust and this level represents what we call a trust goal. Our model reflects recent calls to adopt a richer, context related, processual perspective to trust research (Lewis \& Weigert, 2012; McEvily, 2011; Searle et al., 2018). We do so by incorporating contextual features of the interpersonal relationship in which trust occurs (Tomlinson, 2011). Thus far, consideration of the context of the relationship has been restricted to factors such as relationship tenure, shared similarity and reciprocation (Ferrin \& Lyu, 2018). In a departure from this, our model explores how the function of the relationship, in terms of how it fulfils intrinsic or extrinsic needs, is an important determinant of trust. It is the experience of the relationship with another which provides the context that creates trust motivation.

Our theory of trust motivation more comprehensively accounts for trusting decisions in general, including those where individuals trust and cooperate when rational models would suggest they should not (Weber \& Murnighan, 2008). Indeed, models which suggest that trust is a product of trustworthiness and trust propensity have significant difficulties in accounting for split second trust decisions (Willis \& Todorov, 2006) or those which are made without sufficient logical evidence and thus appear to be irrational (e.g., Baer et al., 2018; Pillutla, Malhotra, \& Murnighan, 2003). These models also fail to explain how visible behavior that violates trust expectations is overlooked (Robinson, 1996; Tomlinson, 2011) or how trust between untrustworthy individuals leads employees to act in the interests of a work relationship rather than self- or organizational interests (e.g., Aven, 2015). While these acts of trust may appear irrational through the lens of a rational-choice model, we argue that people may trust in these circumstances because of the motives and desires they pursue within their relationships. For this reason, we offer a theoretical framework that extends trust 
theory by zooming in on motivational, intra-individual processes in workplace relationships and moving away from a focus just on the accumulation of trustworthiness information.

We draw on self-determination theory (SDT; Deci \& Ryan, 1985) and control theory (Carver \& Scheier, 1982; 1990; 2000) to build a model of motivated, volitional trust decision making that enables us to open the black box of "willingness to be vulnerable". Our model explains how differing experiences in a relationship can motivate individuals to trust certain people over others and considers how they nurture and manage that trust goal on an ongoing basis. Through a process of trust goal setting, we argue that trust motivation can be driven by motivational forces (intrinsic and/or extrinsic) which are derived from perceptions and experiences of the particular relationship in question. We then propose that once an individual experiences trust motivation, efforts to build and maintain trust in the relationship will be self-regulated (Carver \& Scheier, 1982). In doing so, we introduce the concept of trust regulation, a term we use to describe the self-management and transformation of trust cognition, affect and behavior towards the achievement of a trust goal.

These two phases of trust motivation can be mapped onto traditional models of trust (see Figure 1). Specifically, trust goal setting is a pre-decisional process occurring alongside, and interacting with, the consideration of trustworthiness. Trust regulation, on the other hand, is a post decisional process which facilitates the attainment of a trust goal via different regulatory strategies and through managing the feedback loop between trust outcomes and subsequent trust decisions. In distinguishing between two distinct phases of trust motivation, trust goal setting and trust regulation, we offer a more progressive understanding of the intraindividual processes that an individual engages in when new or discordant information regarding that relationship is perceived. In the following sections, we consider how motivation theories can allow us to better understand the why and how of the trust process. 


\section{Interpersonal Trust}

A prominent definition provided by Mayer et al. (1995, p. 712$)$ defines trust as " the willingness of a party to be vulnerable to the actions of another party based on the expectation that the other will perform a particular action important to the trustor, irrespective of the ability to monitor or control that other party". This definition combines two important aspects of trust which are common to the majority of trust perspectives, a willingness to be vulnerable and a belief about the other party's intentions (Lewicki \& Brinsfield, 2012). Prevailing theoretical models of trust (e.g., Mayer et al., 1995) suggest that this willingness, and the expectations on which is it based, is driven predominantly by a rational judgement of the trustworthiness of the other party, also known as the trustee. This judgement is generally portrayed as an aggregated evaluation of the trustee's ability, benevolence and integrity (Mayer et al., 1995) and the dominant view in the literature is that this is the primary determinant of trust (Baer \& Colquitt, 2018).

Despite this general consensus, questions have started to be posed about the validity of this approach. For example, Li (2012) observes that if trust relies largely on expected trustworthiness, the two become a mirror image, thus redundant. Indeed, traditional trust models have been critiqued by Möllering and colleagues for inadequately capturing the ongoing process of trust as a willingness to be vulnerable over and above the passive perception of, and reaction to, trustworthiness (Möllering, 2001; Möllering, 2006; Nikolova, Möllering, \& Reihlen, 2015). In reality, evidence suggests that trust cannot be so easily prescribed and trustors often show deviations from what they should be doing given the evidence available (McKnight, Cummings, \& Chervany, 1998; Pillutla et al., 2003; Weber et al., 2004). For example, in some cases individuals may trust one person over another despite both seeming equally trustworthy or, in the case of long-term relationships, trust can appear habitual, persisting in the face of contrary evidence. In traditional models, any additional 
influences are treated predominantly as "temporary irrationality" and a phenomenon that should appear with less frequency in daily trust encounters (Schoorman, Mayer, \& Davis, 2007, p. 349).

We argue that the literature would benefit from a more dynamic and inclusive approach where it is possible to examine why people show different strategies and motives in their decision to trust in new and ongoing relationships. In particular, a motivated model of trust allows us to consider the motives underlying a choice to be vulnerable as well as the volitional planning and striving inherent in the pursuit of trust (see Heckhausen, 2007 for a discussion of motivation and volition).

\section{Trust Motivation}

Motivation, as the determinant of the initiation, form, direction, duration and intensity of behavior (Pinder, 1998), is a psychological process that is central to understanding human beings. Given that the decision to trust portrayed here is a volitional process, based on an individual's interaction with his/her social environment, a consideration of motivation is essential. Although existing trust research has not entirely neglected the topic of motivation, the role of motivation in traditional trust models is primarily portrayed as an assessment of the motivation of the other; that is the other party's benevolence. Benevolence is the perception that the other party is motivated to act in the trustor's interests beyond any “egocentric profit motive" (Mayer et al., 1995, p. 718; Peters, Covello, \& McCallum, 1997, p. 44). From these perspectives, the trustor's motivation is considered only to the extent to which his/her goals are aligned with the trustee's. This alignment is also reflected in identification-based trust (Lewiki \& Bunker, 1996), although the discussion of trustor motivation is not explicit and trust is conflated with the motivational and knowledge-based cognitions it is based on. 
A small body of literature has explored how trustor motivation may be introduced as a more central component of the trust decision making process. In this literature, establishing and maintaining key trust relationships is seen to be a goal worth pursuing - either as a means to achieve other more distal goals such as friendship and positive social identity, or as a core goal itself because to trust and to be trusted "feels good". Williams (2001, p. 387) introduces the concept of a motivation to trust as "the desire to view another person as trustworthy enough to be relied on". Accompanying this desire is the likelihood that trustors are willingly (or volitionally) crafting and engaging with their social environment to maintain or alter trust levels in relationships. Importantly this implies that individual differences in trust building do not only stem from a general propensity to trust others but are also driven by relationshipspecific goals which are targeted at a specific referent.

Similarly, Weber and colleagues (2004) examine the role of motivation in trust decision making as a potential explanation for trust behavior that involves high levels of vulnerability in the absence of an opportunity to properly evaluate trustworthiness. They propose that seemingly irrational trust decisions, such as high risk taking in new relationships, are underpinned by motivated attributions of trust cues in an effort to alleviate anxiety in high dependency relationships. In this view, attributions of trustworthiness are affected by goals and preferences and hence motivation becomes a causal factor in the trust decisions (see also Kruglanski, 1996; Kunda, 1990). In line with Williams (2001), Weber and colleagues agree that this motivated form of trust influences the cognitive processing of whether the other party is trustworthy enough to justify making themselves vulnerable.

While the above authors have taken initial steps towards unravelling the motivational processes involved in trusting, their focus on why and how the trustor is motivated to see the other as 'trustworthy enough' has been relatively narrow. To illustrate this further, Williams (2001) considers exclusively the affective dimensions underlying the motivational tendency 
to distinguish, and thereby cognitively relate to, in and out-group perceptions. Meanwhile, Weber et al. (2004) examine how a limited number of contextual conditions, such as dependency in the relationship, motivate the cognitive processing of information. Both examples reflect trust as a motivated and goal driven decision with a clear focus on how motivation (and affect) shapes information processing. Building on this approach, we seek to explore a wider range of motivational drivers that influence trust motivation. Further, we consider the role of motivation and volition beyond the initial processing of trustworthiness or initial trust attributions.

\section{A motivated model of organizational trust.}

We consider trust motivation to be a dynamic state formed in response to the relational and contextual characteristics of a specific dyadic relationship which directs individuals in how they approach the ongoing decision to trust. Our model (see Figure 1) begins with the motivational drivers that are likely to be influential in workplace relationships. These drivers, which are unique to the trust motivation model, provide a basis for trust motivation and are likely to involve issues such as access to organizational resources and fulfillment as a result of a working relationship. It is important to note at this stage that our model portrays trust as a volitional willingness to be vulnerable with three key antecedents: trust motivation, trustworthiness and trust propensity.

We conceptualize trust motivation as an additional, direct antecedent of trust that occurs alongside the assessment of trustworthiness and the impact of trust propensity as represented in dominant trust models such as Mayer et al. (1995). In addition, and in line with Weber et al. (2004), we also expect that trust motivation will have an indirect impact on trust through its influence on trustworthiness perceptions. For instance, in work relationships where trust motivation is high, a trustor will be more willing to be vulnerable in the first instance in order to achieve the level of trust s/he deems necessary to build or maintain a 
relationship that fulfills a particular function for him/her. However, s/he will also be more likely to see his/her colleague as trustworthy thus supporting the decision to trust even further. As such, we argue that cognitive and motivational processes interact to influence trust and that the motivational drivers of trust act as a regulating principle in line with which cognitions about trustworthiness are formed.

P1. Trust motivation is positively related to trust through two key pathways a) as a direct antecedent, and b) via trustworthiness thus influencing trust through a process of motivated cognition.

Finally, and going beyond current trust models, we analyze how the decision to trust is stabilized and regulated (consciously or unconsciously) over time - a process that will be explored in detail in the trust regulation section of our paper. In the remainder of the paper, we explore how motivation impacts the extent to which individuals strive to build and maintain trusting relationships (pre-decisional phase) and building on this, the planning and adaptation they use to achieve trust (post-decisional phase).

Insert Figure 1 about here

\section{Trust Goal Setting}

The first phase of our model of trust motivation relates to the pre-decisional phase highlighted in Figure 1. We propose that SDT offers a useful lens for systematically examining why individuals are motivated to trust in some relationships more than others. SDT also allows us to separate these motivations from the trust decision itself, thus capturing the distinction between trust as a volition and the motivation driving it. Hence, in using SDT, we build on the original conceptualization of trust motivation (Williams, 2001) and propose 
that the desire to trust has a variety of motivational drivers and that this differing basis of trust motivation influences its stability.

The use of SDT to understand motivation as a driver of behavior in relationships has its early roots in the romantic relationship literature (e.g., Blais, Sabourin, Boucher, Vallerand, 1990; Seligman, Fazio, \& Zanna, 1980) and has expanded over the years to a general theory on human motivation and interpersonal relationships (Weinstein, 2014). The theoretical and empirical support for SDT in demonstrating how psychological needs, motivation and relationship outcomes (such as trust) are interlinked offers the potential for important insights into workplace trust. In its relationship motivation theory, SDT explains how different qualities of a relationship are linked to humans' three basic psychological needs for relatedness, autonomy and competence (La Guardia \& Patrick, 2008). Furthermore, SDT also shows how these three needs lead to different types of motivation that are more or less persistent as drivers of goal directed activity. We incorporate these ideas within our model of trust motivation.

According to SDT, these basic psychological needs explain relationship directed motivation (and behavior) as well as relationship qualities (Deci \& Ryan, 2014). The need for relatedness is a natural starting point for relationships as it is portrayed as the desire to feel connected to others - to love and care, and to be loved and cared for (Deci \& Ryan, 2000). It is often characterized by the feeling that thoughts and feelings in a relationship are mutual and shared (see also Baumeister \& Leary, 1995). Yet SDT also clearly argues that deep and meaningful interpersonal connections are further dependent on whether the needs for autonomy and competence are satisfied. Hence autonomy concerns the feeling of choice with respect to a behavior or experience one is engaged in (e.g., de Charms, 1968); a relationship partner who is felt to be manipulative or overbearing might thwart this need. Competence refers to feeling effective and being acknowledged for this effectiveness (Deci \& Ryan, 
2000); a relationship partner showing a laissez-faire attitude or providing mainly negative feedback in interactions might undermine feelings of competence.

Need satisfaction in relationships can be linked systematically to motivation, and as we will argue to trust motivation. SDT distinguishes between intrinsic, controlled extrinsic and autonomous extrinsic motivation (Gagné \& Deci, 2005). We propose that intrinsic trust motivation will evolve in highly satisfying relationships where individuals invest effort into maintaining or establishing trust because they find it enjoyable, interesting and being part of that relationship is its own reward. Similarities can be seen between trust based on an intrinsic motivation and the concept of affect-based trust (McAllister, 1995). McAllister (1995) argues that affect-based trust involves genuine care and concern along with a belief in the intrinsic value of a relationship. Importantly, though, we use SDT to separate this relational quality from the decision to be vulnerable and propose that it is better represented as a motivational antecedent of trust.

While willingness to be vulnerable in a relationship may be supported by intrinsic forces, not all relationships are likely to be intrinsically satisfying. Instead, extrinsic motivational drivers within the context of a relationship might involve a desire to make oneself vulnerable in order to attain or avoid some separable consequence. As such, extrinsic motivation reflects a more instrumental form of goal-directed behavior, dependent upon the perception of a contingency between the behavior and a desired outcome (Gagné \& Deci, 2005). Extrinsic trust motivation can take on different forms depending on the extent to which it is experienced as autonomous (still satisfying psychological needs to quite a high degree) versus controlled. For instance, an external controlled trust motivation might be driven by perceptions of dependence and asymmetries of dependence within the relationship similar to conceptualizations of calculus-based trust (e.g., Lewicki \& Bunker, 1996). When an individual wants a resource the other party possesses (e.g., status, information, affiliation) 
it leads to a feeling of dependency, an intention to reciprocate (Weber et al., 2004), and a motivation to behave strategically in a pro-relationship manner.

Alternatively, extrinsic trust motivation might be experienced as a more selfdetermined, autonomous goal characterized by value congruence and identification within the relationship with parallels to Lewicki and Bunker's (1996) identification-based trust. This form of extrinsic trust motivation is in line with the SDT concept of identified motivation whereby goals are pursued because they are congruent with personal core values and goals. In addition, this form of extrinsic trust motivation may involve a sense of relational identification whereby the trustor feels their work identity is to some extent defined by being part of this dyad (Sluss \& Ashforth, 2007). When an individual feels a sense of identification or value congruence with a work colleague, we argue that this will create an autonomous motivation to build and maintain a trusting relationship with that colleague.

Importantly, intrinsic and autonomous extrinsic motivation both rely on need satisfaction in relationships - and the resulting trust motivation has an influence on the dynamics of the interpersonal relationship. The core hypothesis here is that intrinsic and autonomous extrinsic motivation cause a more stable motivation to persist with a relationship (Deci \& Ryan, 2014) than controlled extrinsic motivation and that this relates to a different will to uphold trust. A wealth of research demonstrates that intrinsic and extrinsic, autonomous motivation engenders greater persistence (Deci \& Ryan, 1985; Vansteenkiste, Simons, Lens, Sheldon, \& Deci, 2004). More specifically, intrinsic and autonomous relationship motivation has been demonstrated to lead to more positive and adaptive affective and cognitive evaluations (Blais et al., 1990). Finally research has shown that when people commit to, and persist at relationships autonomously, they will likely experience the relationships to be of higher quality and thus more satisfying during the relationship process (Knee, Lonsbary, Canevello, \& Patrick, 2005; Knee, Lonsbary, Canevello, \& Patrick, 2007). 
Accordingly, trust motivation and the resulting willingness to be vulnerable should be most robust when they are based on intrinsic motivation than on identified trust motivation which in turn would be less fragile than trust based on controlled extrinsic motivation. For instance, followers who experience an intrinsic motivation to trust their leader due to the enjoyment that they get from that relationship would be likely to maintain trust motivation in the face of changing trustworthiness information. In contrast, followers with controlled extrinsic motivation based on the influence a leader has on career progression prospects may be more likely to experience a reduction in trust motivation in the same circumstances.

P2: Intrinsic and/or extrinsic motivational drivers are positively related to trust motivation and trust goal setting.

P3: Employee trust goals that are shaped by intrinsic trust motivation will be more robust and persistent than those shaped by autonomous extrinsic trust motivation which will be more robust and persistent than those shaped by controlled extrinsic trust motivation.

Once trust motivation goals have been set, an individual must then consider how s/he will implement and achieve the goal to build or maintain a specific trust relationship. The following section will explore this post decisional process as illustrated in Figure 2.

Insert Figure 2 about here

\section{Trust Regulation}

Although mainstream trust literature has largely neglected the concept of motivation, the idea that trust has an element of self-regulation did feature in early definitions of trust. For instance, Flores and Solomon (1998, p. 212) describe trust as a social, personal and 
emotional practice which we "create for ourselves". Similarly Cook and Wall (1980) introduce trust as a willingness to ascribe good intentions to the trustee. Unfortunately, this view of the trustor as an active participant in the trusting process has been somewhat diluted and even ignored in more recent conceptualizations. We believe that this self-regulated element is a vital and central aspect of how trust functions in interpersonal work relationships. We draw on control theory (Carver \& Scheier, 1982; 1998) to propose that trust goal setting is followed by a series of self-regulatory steps in the pursuit of this trust goal. As such, trust regulation represents a dynamic account of how individuals achieve their trust goals and is a volitional state focusing on the discrete level, intra-individual processes that follow from the decision to trust.

Self-regulation refers to the processes undertaken in attaining and maintaining personal goals (Vancouver \& Day, 2005) and provides an account of the dynamic interplay and management of cognitive, affective and behavioral resources following goal setting (Carver \& Scheier, 1998). These internal processes allow individuals to adapt to changes in their situation and environment in order to assess progress and continue in their goal pursuit (Lord, Diefendorff, Schmidt, \& Hall, 2010). It also recognizes the reciprocal effects of goal focused affect, cognition, and behavior offering a framework for exploring the within person processes that allow trust emotion, cognition and behavior to interact, an issue that has been poorly addressed in the current literature (van Knippenberg, 2018). The theory is temporally sensitive and thus is sympathetic to a processual account of individual-environment interaction. These factors would appear to be fundamental to our understanding of how trust motivation goals are established and how individuals monitor and manage trust relationship cues rather than simply reacting to changes in trustworthiness.

\section{Control theory.}


Control theory adopts a systematic approach to the study of the hierarchical nature of goals and the dynamics of intra-individual, goal related regulation over time. The central concept of control theory is the discrepancy reducing feedback loop which consists of four elements: an input function, a standard reference value, a comparison function and an output function (Carver \& Scheier, 2000). When applied to the trust process, the input function represents the current perception of trust in the other party and the risks inherent in the trust decision. The standard reference value represents the trust goals discussed earlier that act as a desired end state which the individual would like to work towards. The comparison function involves an evaluation of the gap or differences between what is perceived in the input function and the standard reference value. In trust motivation, this comparison would involve comparing current trust levels to the level of trust necessary to achieve the trust goals. Once this comparison has been made, any divergences detected initiate the output function and lead an individual to self-regulate his/her cognition, affect or behavior to reduce this discrepancy. In the case of a discrepancy between trust goals and current levels of trust, an individual is prompted to take action which may include regulating his/her behavior (e.g., exert less effort into trust-building), cognitions (e.g., how s/he processes trustworthiness cues) or emotions (e.g., suppress his/her emotional reaction) in an effort to lessen this discrepancy. As depicted in Figure 2, the processes described occur across both the goal setting and goal regulation phases of our trust motivation model.

According to control theory, these processes occur through an action feedback loop which links original goal establishment with goal directed activities and monitoring of progress toward the goal in the wider context of the environment (Vancouver, 2008). This goal monitoring activity provides early and ongoing cues about the probability of success of the adopted strategies toward overall goal attainment. This is particularly important in the case of trust regulation where the desired end state or standard is not necessarily one with a 
discrete end point and trust regulation can be expected to continue for the duration of any relationship in which trust motivation exists. It is important to note at this point that goal monitoring activities can operate at varying levels of consciousness. Conscious and unconscious monitoring represent dual processes which can occur in parallel. Which path is activated will depend on how the discrepancy was perceived with the response typically be enacted at a similar level of processing (Klein, 1989). For the most part, trusting in established relationships may involve unconscious monitoring of information about the other person and the environment. Goal progress information is more likely to be processed in a conscious manner if the goal is highly valued, the situation is unfamiliar, the information is significantly different from what is expected, or if a third party or environmental cue makes that information more salient (Klein, 1989; Taylor, Fisher, \& Ilgen, 1984).

\section{Regulating trust cognition, emotion and behavior.}

We have argued that individuals are likely to experience differing levels of trust motivation across their work relationships and set trust goals according to this motivation. As a result within each relationship, certain trust cognitions, emotions and behaviors are likely to be more desirable than others. We use the term trust cognitions to describe all perceptual, evaluative, reasoning and judgmental processes involved in a trust decision. Trust emotions refer to intense affective states, either positive or negative in valance, which are tied to the experience of trust in a particular relationship. While trust behavior can be defined as the actions taken by individuals once they have made a decision to be vulnerable to another party. Cognitions, emotions or behaviors which are less desirable (such as information regarding the low trustworthiness of the other party) are likely to be detected as discrepancies which represent movement away from the desired goal of establishing or maintaining a trusting relationship. According to control theory, this will evoke discrepancy reducing strategies (Brett, Northcraft, \& Pinkley, 1999) in an attempt to bring the environment in line 
with the standard. The discrepancy reduction process can occur at either a conscious or automatic level. Automatic discrepancy reduction strategies may be likely in frequently encountered discrepancy situations while more conscious, systematic processing may be activated to deal with discrepancy in less familiar situations.

An example discrepancy reducing strategy would be that of cognitive bias which will influence the processing of cognitive cues that may otherwise be perceived as leading to negative expectations and an unwillingness to be vulnerable, when trust motivation is high. Take for example, a leader with high trust motivation. This leader may base his/her judgements on the information available but construe it in the most positive light to allow him/her to attain the trust goal of wanting to trust a particular subordinate. Such a discrepancy-reducing strategy reflects motivated reasoning wherein the leader engages in cognitive restructuring through the effortful but biased processing of incongruent information in order to defend his/her self-interest (Chen \& Chaiken, 1999). This process of motivated reasoning is reflected in the work of Williams (2001) who argues that a high motivation to trust should lower the threshold of trustworthiness necessary for a positive trust decision whereby ambiguous cognitive information should be perceived as trustworthy.

Similarly, trustors experiencing an emotion-eliciting event could evoke an emotion regulation strategy if a discrepancy is detected wherein affective resources are deployed. Returning to our leader with high trust motivation for a given subordinate, noting unexpected unfavorable trust cues will lead to the experience of a negative emotion. For example, an employee may communicate to the leader that s/he has failed to meet a deadline as promised, triggering frustration. The discrepancy or deviation from the expected value will require some regulatory adaptation, affective in this instance. If the unfavorable cue is regarded as potentially ambiguous or a 'one-off' in contrast to a consistent and cross-situational behavior, then the regulatory adjustment might be minor involving defensive strategies such as 
distraction or suppressing the feelings of frustration (Webb, Miles, \& Sheeran, 2012), thus facilitating a return to a steady state.

Similar to cognition and affect, the regulation of trust behavior or action is aimed at steering effort and focus back to the reference value after a discrepancy has been noted. Where the discrepancy is negative then regulatory adjustment is required which may involve overriding automatic behaviors and systematically adopting behaviors which are likely to facilitate an effective trust relationship. When individuals have set a goal to maintain trust in a particular relationship, engaging in approach oriented trusting behavior is an important tool in building and sustaining that relationship. In addition, individuals should avoid displaying behavior which is typically associated with distrust and suspicion (Williams, 2001; Williamson, 1993). In contrast, where the discrepancy is positive, current behavior would appear to be exceeding expectation so some dampening of effort may be required to achieve the required state, a process Carver and Scheier (2011) refer to as 'coasting'. Coasting may be particularly relevant in low trust motivation relationships where an individual perceives that $\mathrm{s} / \mathrm{he}$ is engaging in high levels of trust behavior (e.g., disclosing personal information to a work colleague) and decides to rein his/herself in.

In summary, we argue that trustors will compare incoming trust cues to their referent trust goal in line with the comparator function outlined by control theory. Trustors who detect discrepancies in trust related cognitions, emotions, or behavior in their workplace relationships will then initiate the output function to bring their cognition, emotion or behavior in line with the referent trust goal.

P4: Employee detection of discrepant trust cues in the form of trust cognition, emotion and/or behavior will be positively related to employee trust regulation in an effort to reduce those perceived discrepancies. 


\section{Reciprocal interaction of trust regulation processes.}

Although we have outlined our arguments for the regulation of trust cognitions, emotions and behaviors separately above, in reality, and as depicted in Figure 2, these processes are inextricably linked and interwoven in an ongoing process of mutual influence. We expect within any given trusting relationship for there to be the active regulation of these three core processes at varying levels of automatic or effortful processing. Which regulatory process (i.e., cognitive, affective or behavioral regulation) is deployed, and when, is more variable and dependent on the given context.

While it is often accepted that the experience of cognition and emotion are inextricably linked this has not been reflected in much of theoretical and empirical trust research (van Knippenberg, 2018; and for a notable exception see Jones \& George, 1998). If we consider an example of a leader with high trust motivation, when experiencing frustration towards a follower for not meeting a deadline the leader may choose to suppress that emotion and then reappraise the importance of the deadline as less critical. As such, emotion suppression can be used in conjunction with cognitive restructuring to reduce the discrepancy so to achieve the desired state for the trust goal. The pattern of influence between cognition and emotion may also occur in the opposite direction with affective cues influencing trustworthiness decisions (Jones \& George, 1998). This process of affect-as-information (Schwarz, 1990), creates a lens through which behavior of the other party is judged (Lount, 2010). In the case of trust regulation, cues and signals that indicate that cognitive expectations are not being met will typically provoke a negative emotional experience.

Patterns of reciprocal influence can also be seen between the regulation of behavior and that of emotion and cognition. Simon (1967) suggests that goal related emotional experiences are discrepancy cues that work like an error signal which will motivate an 
alteration in self-regulatory processes which typically leads to a behavioral adjustment. In this way, the regulation of behavior in response to emotion regulation becomes interwoven, and the action outcomes should typically result in a change to the affective experience. Similarly, the interaction between cognitive and behavioral regulation is well established in both the self-regulatory and trust literature. In self-regulation theory, cognitive goal setting processes form the basis for directing behavior (Frese \& Zapf, 1994). Traditional trust models typically position trust decision making as a driving force of risk related relationship behaviors (e.g., Mayer et al., 1995), which then feed into subsequent trust decisions, thus capturing the reciprocal relationship between action and cognition.

A core tenet of control theory (Carver \& Scheier, 2000) is that goals operate within a hierarchical framework at different levels of abstraction (Lord et al., 2010). Within such a structural model, trust relationship maintenance would represent a higher-level goal while cooperating on a specific task to demonstrate trust would be considered a lower-level goal. While the superordinate goal of these various self-regulatory mechanisms is to maintain the trust relationship, goals are hierarchically nested such that lower level, subordinate goals contribute to the attainment of this more abstract long-term goal (Carver \& Scheier, 1982). Applying this to our discussion of trust regulation, trust behavior used to achieve a lower level goal such as sharing of information with a colleague contributes to the higher order goal of maintaining a high trust relationship. While this is an example of bottom-up control (lower-level goals supporting higher-level goals), top-down control and sequential linkages between goals at the same level can also occur (Lord et al., 2010). For example, a higher level goal of maintaining a high trust relationship with one's leader will support goal setting at lower levels such as cooperating with that leader on a key project or supporting a manager's new initiatives within the workplace. 
Given this evidence, we propose that trust regulation involves an ongoing process of reciprocal influence between cognitive, affective and behavioral processes. The experience and regulation of any one of these processes is likely to have consequences for the other two. The extent of these consequences will be reflective of the degree and intensity of the discrepancy, the extent to which the episode is relevant across multiple situations, and the centrality of the episode in question to the higher order goal of a strong trusting relationship. For instance, trustors who detect a large, global discrepancy in current and desired levels of trust will need full engagement of all three regulatory systems to adapt to that discrepancy. In contrast, a lower level specific discrepancy, such as undesirable behavior regarding information sharing on a particular task, might be dealt with through more automatic engagement of only the behavioral regulatory system without the need to regulate emotion or cognition. As such, the level of a goal within the overall hierarchy, where a discrepancy is detected, is a key determinant of the range and effectiveness of the self-regulation strategies employed in pursuit of trust goal attainment.

P5: Throughout the duration of a relationship, regulation of trust cognition, emotion and behavior will interact over time in a pattern of reciprocal influence striving for trust goal attainment.

P6: Trust goal level will moderate the relationship between activation of one trust regulation system and activation of the other two systems such that higher level goals will strengthen the relationship and lead to more global regulatory activation.

\section{Changing goals in response to discrepancy cues.}

In our previous discussion, we have focused predominantly on discrepancy reduction strategies that involve regulating trust cognitions, emotions and behavior to bring them in line with the standard reference or trust goal. While we describe an iterative, fluid process of self- 
regulation it is important to acknowledge that the goals within this process are not static (Carver \& Scheier, 1982). Rather, goals are also part of the regulatory system and will be subject to change as the individual interacts with her or his environment over time (Vancouver, 2008). This is particularly pertinent to trust motivation as the goal of a trusting relationship is not one with a discrete end point.

As noted by Carver and Scheier (2000), reference goals are likely to be adjusted and adapted as individuals gain experience in a particular domain. They argue that these reference shifts are caused by a gradual accumulation of discrepancy cues which cause individuals to shift their standard upwards to create more challenge or downward to reduce the level of challenge. In the context of trust motivation, trust goals might change gradually as a result of repeated interactions in a process similar to that predicted by traditional trust models (e.g., Lewicki \& Bunker, 1996; Mayer et al., 1995). Gradual reference shifts might therefore occur in a relatively automatic fashion over the course of a relationship. Equally, consistent large discrepancies or external disturbances, which are accompanied with a change in risk, may cause an individual to step back and assess his/her reference goal more systematically (Carver \& Scheier, 1981; 1990). When the individual feels that continued goal pursuit is unlikely to result in success s/he may disengage from that goal; this disengagement process is relatively simple for a lower order goal but more complex and difficult for higher order goals (Carver \& Scheier, 2000). For instance, the decision to abandon a lower order trust goal of cooperating on a specific work task might be made relatively quickly and the trustor might shift his/her focus to using a different strategy to achieving the higher order goal. However, where consistent discrepancies or disturbances suggest a change should be made to a higher level goal such as reducing trust motivation in a highly instrumental colleague, this decision is likely to involve greater effort and potential distress for the trustor. 
P7: Employee detection of an accumulation of discrepant trust cues will be positively related to a reassessment of current trust and risk levels and to trust goal adaptation.

\section{Changing goals in response to external disturbance.}

As shown in Figure 2, it is proposed that external disturbances can influence the trust regulation process. Discrepancies brought about through external disturbances are detected via the ongoing monitoring of the environment by the trustor. This monitoring can be more or less active depending on the salience of the discrepancy which is likely to be influenced by the valence of the goal in question and the frequency of the feedback received regarding that discrepancy (Klein, 1989). Highly valued goals require more active monitoring of discrepancy information and frequent, consistent feedback about a discrepancy is likely to encourage more systematic processing of that discrepancy, particularly when threats in the environment are salient.

In the context of trust motivation, a key potential form of external disturbance is information concerning risk. A consideration of risk is paramount within the trusting process (Mayer et al., 1995). Assessing the risk in a situation involves a consideration of the context, such as weighing the likelihood of both positive and negative outcomes that might occur (Bierman, Bonini, \& Hausman, 1969). To illustrate how risk may play a role during trust regulation, take the example of a subordinate who, upon receiving a promotion, is now a peer to his/her leader. Such a change in the environment may mean that the former subordinate is less dependent on that relationship, and thus the trusting relationship entails less risk. As such the trust goal may now be driven less by controlled extrinsic motivation (due to the dependence felt), and instead by other motivating forces, if they are also present.

As previously stated, both intrinsic and extrinsic reasons for trust motivation can coexist within a relationship. Which of these is the primary driver of goal setting can change 
during the course of that relationship. In the above example, the trustor may abandon the trust goal due to the lack of extrinsic drivers. If, however, the relationship with this colleague enables need satisfaction, the trust goal may be adapted to reflect these intrinsic motivating forces. Further to this, we argue that extrinsic goals are more vulnerable to change and more malleable compared to their intrinsic counterparts. There are two reasons for this, first, dependence and risk are inextricably linked, in that the greater the risk in trusting another (due to their heightened power or influence), the more dependence experienced. As such, if the level of risk were to shift, this would have a greater effect on extrinsically motivated trust. Second, while the outcome expectancy of a goal is a critical consideration following a disturbance, so too is the valence of that goal (Klein, 1989). Intrinsic goals are likely to be more valued by the trustor, and thus would be considered to be more robust and enduring.

Drawing on the work of Brett et al. (1999), we propose that changes to the standard reference goal can be made in one of two directions. First, trustors might adapt the content of their goal by changing the level of trust expected within the relationship. In this way, trustors can strive to attain a more optimal level of trust that will allow for an effective working relationship but limit the extent of their vulnerability to the trustee. Second, trustors might choose to shift the level of the goal itself within their overall goal hierarchy to provide perspective on the discrepancies detected. For instance, if the original reference goal is to maintain a trusting relationship a trustor could consider why s/he has set this goal and shift his/her focus to a higher, more abstract level such as achieving a successful working life. In moving to a higher level of abstraction, the trustor can consider alternative methods of achieving his/her goal. Alternatively, s/he could remain focused on maintaining this particular relationship but move the reference goal to a lower level by making the trust goal more specific. This could be achieved by contextualizing the focus of his/her trust by specifying that $\mathrm{s} / \mathrm{he}$ aims to trust the other party to complete a particular task. 
P8: Large discrepancies or external disturbances will be positively related to trust goal adaptation, and negatively related to trust goal persistence via the input function.

P9: The relationship between the input function and trust motivation will be moderated by the motivational driver such that more extrinsic motivational drivers will strengthen the relationship and increase the likelihood of goal adaptation.

\section{Discussion}

The motivational processes underlying trust have received very limited attention in the literature. Further, traditional trust models fail to account for the volition implied by a willingness to be vulnerable, the seemingly irrational or habitual range of trust decisions and do not capture the ongoing changes in the regulation of trust over time. Instead a simpler and less holistic representation of trust is offered. In this paper we propose a dynamic process model of trust decision making that highlights the critical role of motivation in the willingness to be vulnerable and explores the interaction of trust cognition, affect and behavior. In order to understand how motivation can influence trust in both pre and post decisional phases, we incorporate theories of self-determination and self-regulation and contend that individuals engage in a process of trust goal setting and trust regulation in order to maintain effective work relationships. In doing so, we break new ground within the trust literature through offering a deeper understanding of the processes that influence trust decisions. Importantly our model incorporates the accumulated knowledge on the dispositional (trust propensity) and interpersonal (trustworthiness characteristics) drivers of trust in combination with intra-individual motivational processes.

\section{Theoretical Contributions}


The impetus for this paper comes from the need for trust theory to adopt a more integrative approach to trust research through considering other, related processes, which may be operating during trust decisions (Lewis \& Weigert, 2012). In a departure from the traditional models we move away from a preoccupation with trustworthiness and embrace motivational processes as an alternative explanation for what may also be driving the decision to trust. As we have argued, we propose that considerable, novel insights can be achieved through considering the role of the trustor as an active participant in building and maintaining his/her relationships, through both trust goal setting and trust regulation. Our trust motivation model significantly extends current understanding of trust in four key ways.

First, our model explores the motivational and volitional nature of the willingness dimension of the definition of trust. The use of words like willingness and intention have long implied that volition is a defining feature of trust but until now, trust theory has focused on the positive expectations aspect of the conceptualization to the point where willingness to be vulnerable has been reduced to a reaction to trustworthiness. We provide the first in-depth analysis of motivated trusting as an ongoing process that can be monitored, evaluated and adapted by the trustor as the relationship progresses. This answers repeated calls from the trust literature to explore trust as a more dynamic, processual variable (Lewicki et al., 2006; Möllering, 2001; Searle et al., 2018). Importantly, these motivational processes, which influence trust, are proposed to occur both alongside and interacting with trustworthiness. Of course, we do not argue that therefore motivation makes cognition unnecessary, but make the argument that motivation and cognition interact, with motivation taking the role of the regulating principle. As such, our framework extends trust theory in a way which compliments what is already understood of the trusting process (e.g., Mayer et al., 1995) and provides insight for trust decision making at all stages of the trust relationship. 
Second, our model draws on SDT to explore the different potential motivations that may underlie a decision to trust. We propose that individuals are motivated to trust certain individuals more than others based on intrinsic or extrinsic drivers, even if both are seemingly equal in terms of trustworthiness. In doing so, we build on the original conceptualization of motivation to trust (Williams, 2001) and explore how the context of the relationship might afford different bases for trust motivation. We also extend the work of Weber and colleagues (2004), who argue that trust might be motivated by perceptions of dependence, and suggest that more autonomous forms of extrinsic trust motivation and indeed fully intrinsic trust motivation are possible. The discussion of motivational drivers of trust significantly expands our understanding of the factors influencing trust decisions and offers a more relational, situated account of trust within a dyad. We have positioned our discussion of these motivational drivers within the existing theory on multidimensional trust. Doing so allows us to demonstrate the utility of SDT in integrating previously segregated areas of the theoretical trust literature while offering an advantage of separating motivation from traditional trustworthiness cues and the decision to be vulnerable. Further exploration of trust goal setting offers a potential avenue for understanding why trust within dyads is not always mutual or reciprocal, a topic of considerable debate and conflicting evidence in the current trust literature (Korsgaard, Brower, \& Lester, 2015).

Adopting a self-regulatory perspective, via the use of control theory, offers a third contribution to the trust literature by embracing a within-person standpoint (Dalal \& Hulin, 2008). This approach overcomes the limitations associated with using traditional theory to understand trust as a dynamic process. As an ongoing process of internal resource management, a self-regulation perspective on trust provides a functional, dynamic account of how trust levels might be expected to change over time, via the ongoing self-regulation of cognition, emotion and behavior. More specifically, our model enables a more fine-grained 
analysis of the often self-reinforcing qualities of trust as it shows the reciprocal effects of the cognitive, emotional and behavioral components of trust as well as the potentially amplifying nature of self-regulation or trust goals. The model also accounts for learning and/or disrupting effects within the trust relationship offering an explanation for why trust is often more robust than expected but also for how fragile it can become once certain thresholds are surpassed. In exploring the role of motivational processes beyond their potential to influence trustworthiness judgements (e.g., Weber et al., 2004), we offer a framework for considering how motivation and trust processes are intertwined over time within any workplace relationship. As the trust literature strives to capture the longitudinal processes of trust, our model highlights the necessity of considering motivation and offers increased understanding for researchers designing empirical work to capture changes as they occur.

Fourth, our model provides a starting point for researchers to explore new avenues of trust research. For instance, the capacity for self-regulatory processes to operate at different levels of consciousness offers a means for incorporating dual process models of information processing and automatic or heuristic forms of trust (McEvily, 2011). Furthermore, the discrepancy feedback loop presents a mechanism for understanding how trust violations or changes in the external environment might be managed by the trustor and the processes involved in persisting with, or abandoning, the goal to trust. While theorists have recognized that every unmet trustworthiness expectation does not lead to breach (Jones \& George, 1998; Luhmann, 1979), the factors that influence this process have not been fully explored (Tomlinson, 2011). Our model incorporates a role for intrapersonal (trust regulation), interpersonal (trust motivation drivers) and to a lesser extent wider contextual influences (via external disturbances) in influencing how unmet expectations and trust breaches might be processed. Importantly, this ongoing process of goal maintenance occurs at multiple levels of 
abstraction representing how individual trustors proactively monitor multiple goals simultaneously, at various levels, in their pursuit of a trusting relationship.

\section{Future Research}

Understanding the role of motivation in influencing trust decisions has important implications for future theory and empirical research in the trust field. Our model has clear implications for empirical research seeking to understand the resilience, stability or depth of trust in a relationship. We have argued that trusting involves a great deal more than a combination of the characteristics of the trustee (trustworthiness) and the trustor (trust propensity). Future empirical work should also incorporate measures of the motivational and volitional aspects of trust. Building a body of empirical evidence on how these factors interact and influence each other over time will represent a significant step forward for trust scholars in understanding the ongoing and active trusting process.

The propositions outlined in our paper provide an initial roadmap for the empirical investigation of trust motivation. This may include the need to track within-person trust processes over time and examine the influence of different types of discrepancy changes in risk perceptions and the effectiveness of different discrepancy reducing strategies. In addition, a number of other avenues are clear at this point. Self-regulation has been presented as an effortful process that requires the use of a finite pool of resources (Muraven \& Baumeister, 2000). As such, it is likely that the regulation of trust cognition, affect and behavior might be impaired if those resources are depleted by other regulatory processes. Future research might investigate how trust regulation is impacted by competing demanding tasks or indeed, competing demanding relationships.

While our model shifts focus on to the trustor rather than a preoccupation with perceived trustworthiness, we should be careful not to completely neglect the trustee. Trust 
motivation is likely to be present for both parties in a relationship. In this paper, we explore how trust motivation might influence the intra-individual processes for a trustor but each party in a dyad also fulfills the role of a trustee. We suspect that trust motivation is likely to influence the effort trustees' invest in signaling trustworthiness to their work colleagues as when trust motivation is high they may wish to appear more trustworthy in order to achieve or maintain their own goal of trust. While these ideas were beyond the scope of our paper we would encourage future scholars to explore this possibility. Furthermore, how does the trustor interpret the motivation of the dyadic other? If, for example, a leader infers that his/her follower only pursues a trusting relationship with him/her due to extrinsic motivation, what are the implications for the leader's own trust motivation? Moving beyond the dyadic level, future research might also consider the context of interpersonal relationships. What is the influence of third parties as a source of information regarding risk and feelings of dependence? Does the availability of alternative trusting relationships make goal abandonment more likely following the detection of a discrepancy? Foa and Foa (1974) discuss the scarcity of resources, wherein if others in proximity may help satisfy needs, individuals may be more likely to abandon their goal rather than engage in self-regulatory processes to minimize the discrepancy created.

Future research should also consider the impact that stable attributes of the individual may have on the trust motivation process. Control theory positions individual differences as a key variable in influencing the meta-cognitive process of goal reappraisal and the decision to persist with or abandon a goal. In any discussion of trust, the most apparent dispositional tendency is that of the propensity to trust, which reflects a general willingness to trust others (Mayer et al., 1995). Empirical evidence suggests that trust propensity is a more important predictor of trust in initial trust decisions and situations where sufficient trust cues are not available (Grant \& Sumanth, 2009; van der Werff \& Buckley, 2017). Research efforts to 
tease out whether the influence of propensity to trust is most prominent in the initial trust goal setting process than in trust regulation would be of interest. There are a host of additional dispositional variables that are likely to be important in this process including an individual's level of autonomy orientation, uncertainty avoidance, risk propensity and regulatory focus.

The literature on trust is growing rapidly and increasingly scholars are considering more nuanced ideas such as the role of distrust, trust development and trust repair. We envision that our model may contribute meaningfully to these intriguing lines of enquiry. For example, how are discrepancies, caused by trust violations, managed via self-regulation? Do they require a more sophisticated and effortful process of self-regulation in order to accommodate a discrepancy of larger magnitude? Self-regulation processes may have an important role to play in terms of identifying the thresholds or tipping points of ongoing relationships as they move from trust to distrust and vice versa. The duration of the discrepancy is also important to consider when it comes to trust repair. Long periods of discrepancies may be more difficult to regulate and diminish the resources available to recover or persist with the trusting goal following a violation.

\section{Practical Implications}

The literature is clear, trust is a critical determinant of successful, high quality, working relationships (Dutton \& Ragins, 2017) and performance across many levels (Fulmer \& Gelfand, 2012). Attempts to improve trust relations should take considerable time and effort according to traditional models of trust given that its primary predictors require repeated interactions (trustworthiness perceptions) or, in the case of trust propensity, are relatively stable and difficult to influence. While repeatedly showing yourself to be trustworthy is one meaningful way in which a leader can harness employee trust, our model 
of trust motivation brings to light other options. Most notably, organizations and leaders should be looking to provide conditions which foster need fulfilment within relationships to facilitate the development of the more powerful autonomous forms of trust motivation. Our model suggests trust will be robust and persistent in relationships where satisfaction of autonomy, competence and belongingness is high and where people genuinely enjoy working together. Hence creating a context that enables need satisfaction, for instance by creating a climate of appreciation and respect (Decker \& Van Quaquebeke, 2015) and by managing performance on the basis of mastery (Bouskila-Yam \& Kluger, 2011) is also likely to strengthen trust.

Seeking to satisfy autonomous extrinsic trust motivation is also an option available to leaders. Indeed, we would argue that many talented leaders intuitively apply this aspect of our model by framing situations in inclusive and morale building ways (see also Foss \& Lindenberg, 2013). For instance, statements like "we are all on the same page" or "we are in this together" are attempts to prime or highlight aspects of value congruence and relational identification that underlie autonomous extrinsic trust motivation. Similarly, athletic teams and allies in combat situations are typically encouraged to unite against a common enemy or to invest effort for the good of their superordinate group again highlighting aspects of identification and goal alignment. Our model offers a theoretical argument for why these appeals are likely to be more influential in building team trust or trust in an organisation than appeals related to access to resources and dependency. In addition, once such a motivation is established, trust is not only more resilient but also possibly extends more quickly - as it should be unconsciously set as the default level in this relationship.

The above suggestions highlight a need for leaders to think beyond the implications of demonstrating trustworthiness and to consider their relationships with followers as an influencer of trust. Providing a need fulfilling environment or highlighting value alignment 
requires a closer consideration of the trustee and their orientation towards the relationship. This broader perspective gives leaders the opportunity to build more resilient relationships that will prove particularly important in situations characterized by high uncertainty or risk, such as setting up new project teams or embarking on a merger. Our model suggests that in such organisational environments, where there is a sudden increase in risk, trust goals and decisions are likely to become particularly salient and be consciously reassessed. Leaders who are reliant purely on the demonstration of trustworthiness may struggle if the nature of the risk requires them to demonstrate, for example, a lack of integrity (e.g., going back on promises made to employees). If high intrinsic trust motivation is present, greater selfregulatory efforts are likely to be deployed by employees in order to maintain a high trust goal. However, organisational leaders who are reliant on extrinsic trust motivation and continually underline the dependency of their employees can at best expect a fragile form of trust where they are unlikely to be given the benefit of doubt.

\section{Conclusion}

In this paper we propose a holistic model of motivated trusting within workplace relationships. Drawing on self-determination theory and control theory we explore the intraindividual processes of trust goal setting and trust regulation. The model we present represents a significant step forward in the trust literature as the first framework to fully explore how individuals might manage trust relationships on an ongoing basis. We argue that individuals will experience a level of trust motivation specific to each working relationship and that this motivation will drive ongoing regulation of trust cognition, emotion and behavior in pursuit of an effective trusting relationship. 


\section{References}

Aven, B. L. (2015). The paradox of corrupt networks: An analysis of organizational crime at Enron. Organization Science, 26, 980-996. doi: 10.1287/orsc.2015.0983

Baer, M., \& Colquitt, J. A. (2018). Moving toward a more comprehensive consideration of the antecedents of trust. In R. H. Searle, A.M. Neinaber, \& S.B. Sitkin (Eds.), Routledge Companion to Trust (pp.163-182). Abingdon: Routledge.

Baer, M., van der Werff, L., Colquitt, J. A., Rodell, J. B., Zipay, K., \& Buckley, F. (2018). Trusting the" Look and Feel": Situational Normality, Situational Aesthetics, and the Perceived Trustworthiness of Organizations. Academy of Management Journal, 61, 1718-1740. doi: 10.5465/amj.2016.0248

Baumeister, R. F., \& Leary, M. R. (1995). The need to belong: desire for interpersonal attachments as a fundamental human motivation. Psychological Bulletin, 117, 497-529. doi: 10.1037/0033-2909.117.3.497

Bierman, H., Jr., Bonini, C.P., \& Hausman, W.H. (1969). Quantitative analysis for business decisions (3rd ed.). Homewood. IL; Irwin.

Blais, M. R., Sabourin, S., Boucher, C., \& Vallerand, R. J. (1990). Toward a motivational model of couple happiness. Journal of Personality and Social Psychology, 59, 10211031. doi: 10.1037/0022-3514.59.5.1021

Bouskila-Yam, O., \& Kluger, A. N. (2011). Strength-based performance appraisal and goal setting. Human Resource Management Review, 21, 137-147. doi: 10.1016/j.hrmr.2010.09.001

Brett, J.F., Northcraft, G.B., \& Pinkley, R.L. (1999). Stairways to heaven: An interlocking self-regulation model of negotiation. Academy of Management Review, 24, 435-451. doi: $10.2307 / 259135$ 
Carver, C.S., \& Scheier, M.F. (1981). The self-attention-induced feedback loop and social facilitation. Journal of Experimental Social Psychology, 17, 545-568. doi: $10.1016 / 0022-1031(81) 90039-1$

Carver, C.S., \& Scheier, M.F. (1982). Control theory: A useful conceptual framework for personality-social, clinical, and health psychology. Psychological Bulletin, 92, 111-135. doi: 10.1037/0033-2909.92.1.111

Carver, C.S., \& Scheier, M. (1990). Principles of self-regulation: Action and emotion. New York: The Guilford Press.

Carver, C.S., \& Scheier, M.F. (1998). On the self-regulation of behavior. Cambridge University Press, New York.

Carver, C.S., \& Scheier, M.F. (2000). Scaling back goals and recalibration of the affect system are processes in normal adaptive self-regulation: understanding 'response shift' phenomena. Social Science \& Medicine, 50, 1715-1722. doi: 10.1016/S02779536(99)00412-8

Carver, C.S., \& Scheier, M.F. (2011). The self-regulation of action and affect. In K.D. Vohs \& R.F. Baumeister (Eds.), Handbook of self-regulation: Research, theory, and applications (pp. 3-21). New York: The Guilford Press.

Chen, S., \& Chaiken, S. (1999). The heuristic-systematic model in its broader context. In S. Chaiken \& Y. Trope (Eds.), Dual-Process Theories in Social Psychology, 73-96. New York: The Guilford Press.

Colquitt, J.A., Scott, B.A., \& LePine, J.A. (2007). Trust, trustworthiness, and trust propensity: a meta-analytic test of their unique relationships with risk taking and job performance. Journal of Applied Psychology, 92, 909-927. doi: 10.1037/00219010.92.4.909 
Cook, J., \& Wall, T. (1980). New work attitude measures of trust, organizational commitment and personal need non-fulfillment. Journal of Occupational Psychology, 53, 39-52. doi: 10.1111/j.2044-8325.1980.tb00005.x

Dalal, R.S., \& Hulin, C.L. (2008). Motivation for what? A multivariate dynamic perspective of the criterion. In R. Kanfer, G. Chen, \& R.D. Pritchard (Eds.), Work motivation: Past, present, and future (pp. 63-100). New York, NY: Routledge.

Decker, C., \& Van Quaquebeke, N. (2015). Getting respect from a boss you respect: How different types of respect interact to explain subordinates' job satisfaction as mediated by self-determination. Journal of Business Ethics, 131, 543-556. doi: 10.1007/s10551-0142291-8

De Charms, R. (1968). Personal causation. New York: Academic Press

Deci, E.L., \& Ryan, R.M. (1985). Intrinsic motivation and self-determination in human behavior. Springer Science \& Business Media.

Deci, E.L., \& Ryan, R.M. (2000). The" what" and" why" of goal pursuits: Human needs and the self-determination of behavior. Psychological Inquiry, 11, 227-268. doi: 10.1207/S15327965PLI1104_01

Deci, E. L., \& Ryan, R. M. (2014). Autonomy and need satisfaction in close relationships: Relationships motivation theory. In N. Weinstein (Ed), Human motivation and interpersonal relationships (pp. 53-73). Springer, Dordrecht.

Dutton, J. E., \& Ragins, B. R. (2017). Exploring positive relationships at work: Building a theoretical and research foundation. Psychology Press.

Foa, U.G., \& Foa, E.B. (1974). Societal structures of the mind. Oxford, England: Charles C Thomas.

Ferrin, D. L., \& Lyu, S. C. (2018). Determinants, consequences and functions of interpersonal trust within organizations: What is the empirical evidence? In R. H. Searle, 
A.M. I. Nienaber, \& S. B. Sitkin (Eds.), The Routledge companion to trust (pp. 65-104). Abingdon: Routledge.

Fiske, S. T. (2004). Intent and ordinary bias: Unintended thought and social motivation create casual prejudice. Social Justice Research, 17, 117-127. doi:10.1023/B:SORE.0000027405.94966.23

Flores, F., \& Solomon, R.C. (1998). Creating trust. Business Ethics Quarterly, 8, 205-232. doi: $10.2307 / 3857326$

Foss, N. J., \& Lindenberg, S. (2013). Microfoundations for strategy: A goal-framing perspective on the drivers of value creation. Academy of Management Perspectives, 27, 85-102. doi: 10.5465/amp.2012.0103

Frese, M., \& Zapf, D. (1994). Action as the core of work psychology: A German approach. In H. C. Triandis, M. D. Dunnette, \& L. M. Hough (Eds.), Handbook of industrial and organizational psychology (pp. 271-340). Palo Alto, CA: Consulting Psychologists Press.

Fukuyama, F. (1995). Trust: The social virtues and the creation of prosperity. Free Press Paperbacks.

Fulmer, C. A., \& Gelfand, M. J. (2012). At what level (and in whom) we trust: Trust across multiple organizational levels. Journal of Management, 38, 1167-1230. doi: $10.1177 / 0149206312439327$

Gagné, M., \& Deci, E.L. (2005). Self-determination theory and work motivation. Journal of Organizational Behavior, 26, 331-362. doi: 10.1002/job.322

Grant, A. M., \& Sumanth, J.J. (2009). Mission possible? The performance of prosocially motivated employees depends on manager trustworthiness. Journal of Applied Psychology, 94, 927-944. doi: 10.1037/a0014391 
Heckhausen, J. (2007). The motivation-volition divide and its resolution in action-phase models of developmental regulation. Research in Human Development, 4, 163-180. doi: $10.1080 / 15427600701662983$

Jones, G.R., \& George, J.M. (1998). The experience and evolution of trust: Implications for cooperation and teamwork. Academy of Management Review, 23, 531-546. doi: $10.2307 / 259293$

Klein, H.J. (1989). An integrated control theory model of work motivation. Academy of Management Review, 14, 10-172. doi: 10.5465/amr.1989.4282072

Knee, C. R., Lonsbary, C., Canevello, A., \& Patrick, H. (2005). Self-determination and conflict in romantic relationships. Journal of Personality and Social Psychology, 89, 997-1009. doi: 10.1037/0022-3514.89.6.997

Knee, C. R., Lonsbary, C., Canevello, A., \& Patrick, H. (2007). The role of need fulfillment in relationship functioning and well-being: A self-determination theory perspective. Journal of Personality and Social Psychology, 92, 434-457. doi: 10.1037/00223514.92.3.434

Korsgaard, M.A., Brower, H.H., \& Lester, S.W. (2015). It isn’t always mutual a critical review of dyadic trust. Journal of Management, 41, 47-70. doi: $10.1177 / 0149206314547521$

Kruglanski, A. W. (1996). Motivated social cognition: Principles of the interface. In E. T. Higgins \& A. W. Kruglanski (Eds.), Social psychology: Handbook of basic principles (pp. 493-520). New York, NY, US: Guilford Press.

Kunda, Z. (1990). The case for motivated reasoning. Psychological Bulletin, 108, 480-498. doi: 10.1037/0033-2909.108.3.480 
La Guardia, J.G., \& Patrick, H. (2008). Self-determination theory as a fundamental theory of close relationships. Canadian Psychology/Psychologie Canadienne, 49, 201-209. doi: $10.1037 / \mathrm{a} 0012760$

Lemay, E.P., \& Clark, M.S. (2015). Motivated cognition in relationships. Current Opinion in Psychology, 1, 72-75. doi: 10.1016/j.copsyc.2014.11.002

Lewicki, R.J., \& Brinsfield, C. (2012). Measuring trust beliefs and behaviours. In F. Lyon, G. Möllering \& M.N. Saunders (Eds.), Handbook of Research Methods on Trust, 29-39. Edward Elgar Publishing Limited.

Lewicki, R.J., \& Bunker, B.B. (1996). Developing and maintaining trust in work relationships. In R. Kramer \& T.R. Tyler (Eds.), Trust in organizations: Frontiers of theory and research (pp. 114-139). Thousand Oaks, CA: Sage.

Lewicki, R. J., Tomlinson, E. C., \& Gillespie, N. (2006). Models of interpersonal trust development: Theoretical approaches, empirical evidence, and future directions. Journal of Management, 32, 991-1022. doi: 10.1177/0149206306294405

Lewis, J.D., \& Weigert, A.J. (2012). The social dynamics of trust: Theoretical and empirical research, 1985-2012. Social Forces, 91, 25-31. doi: 10.1093/sf/sos116

Lewis, J.D., \& Weigert, A. (1985). Trust as a social reality. Social Forces, 63, 967-985. doi: $10.1093 / \mathrm{sf} / 63.4 .967$

Li, P.P. (2012). When trust matters the most: The imperatives for contextualising trust research. Journal of Trust Research, 2, 101-106. doi: 10.1080/21515581.2012.708494

Lord, R.G., Diefendorff, J.M., Schmidt, A.M., \& Hall, R.J. (2010). Self-regulation at work. Annual Review of Psychology, 61, 543-568. doi: 10.1146/annurev.psych.093008.100314 
Lount Jr, R.B. (2010). The impact of positive mood on trust in interpersonal and intergroup interactions. Journal of Personality and Social Psychology, 98, 420-433. doi: $10.1037 / \mathrm{a} 0017344$

Luhmann, N. (1979). Trust and Power. John Wiley \& Sons.

Mayer, R.C., Davis, J.H., \& Schoorman, F.D. (1995). An integrative model of organizational trust. Academy of Management Review, 20, 709-734. doi: 10.2307/258792

McAllister, D.J. (1995). Affect-and cognition-based trust as foundations for interpersonal cooperation in organizations. Academy of Management Journal, 38, 24-59. doi: $10.2307 / 256727$

McEvily, B. (2011). Reorganizing the boundaries of trust: From discrete alternatives to hybrid forms. Organization Science, 22, 1266-1276. doi: 10.1287/orsc.1110.0649

McKnight, D.H., Cummings, L.L., \& Chervany, N.L. (1998). Initial trust formation in new organizational relationships. Academy of Management Review, 23, 473-490. doi: $10.2307 / 259290$

Möllering, G. (2001). The nature of trust: From Georg Simmel to a theory of expectation, interpretation and suspension. Sociology, 35, 403-420. doi:

$10.1177 / \mathrm{S} 0038038501000190$

Möllering, G. (2006). Trust: Reason, routine, reflexivity. Emerald Group Publishing.

Muraven, M., \& Baumeister, R.F. (2000). Self-regulation and depletion of limited resources: Does self-control resemble a muscle?. Psychological Bulletin, 126, 247-259. doi: $10.1037 / 0033-2909.126 .2 .247$

Nikolova, N., Möllering, G., \& Reihlen, M. (2015). Trusting as a 'Leap of Faith': Trustbuilding practices in client-consultant relationships. Scandinavian Journal of Management, 31, 232-245. doi: 10.1016/j.scaman.2014.09.007 
Peters, R.G., Covello, V.T., \& McCallum, D.B. (1997). The determinants of trust and credibility in environmental risk communication. Risk Analysis, 17, 43-54. doi: 10.1111/j.1539-6924.1997.tb00842.x

Pillutla, M.M., Malhotra, D., \& Murnighan, J.K. (2003). Attributions of trust and the calculus of reciprocity. Journal of Experimental Social Psychology, 39, 448-455. doi: $10.1016 / \mathrm{S} 0022-1031(03) 00015-5$

Pinder, C.C. (1998). Motivation in work organizations. Upper Saddle River, NJ.

Robinson, S. L. (1996). Trust and breach of the psychological contract. Administrative Science Quarterly, 41, 574-599. doi: 10.2307/2393868

Schoorman, F.D., Mayer, R.C., \& Davis, J.H. (2007). An integrative model of organizational trust: Past, present, and future. Academy of Management Review, 32, 344-354. doi: $10.2307 / 20159304$

Schwarz, N. (1990). Feelings as information: informational and motivational functions of affective states. Guilford Press.

Searle, R. H., Nienaber, A.M., \& Sitkin, S. B. (2018). Implications for future directions in trust research. In R. H. Searle, A.-M. I. Nienaber, \& S. B. Sitkin (Eds.), The Routledge companion to trust (pp. 536-541). Abingdon: Routledge.

Seligman, C., Fazio, R. H., \& Zanna, M. P. (1980). Effects of salience of extrinsic rewards on liking and loving. Journal of Personality and Social Psychology, 38, 453-460. doi $10.1037 / 0022-3514.38 .3 .453$

Simon, H. A. (1967). Motivational and emotional controls of cognition. Psychological Review, 74, 29-39. doi: 10.1037/h0024127

Simon, H. A. (1990). A mechanism for social selection and successful altruism. Science, 250, 1665-1668. doi: 10.1126/science. 2270480 
Sluss, D. M., \& Ashforth, B. E. (2007). Relational identity and identification: Defining ourselves through work relationships. Academy of Management Review, 32, 9-32. doi: 10.5465/amr.2007.23463672

Taylor, M.S., Fisher, C.D., \& Ilgen, D.R. (1984). Individuals' reactions to performance feedback in organizations: A control theory perspective. In K.M. Rowland, \& G.R. Ferris (Eds.), Research in Personnel and Human Resources Management (pp. 81-124). JAI Press: Greenwich, CT.

Tomlinson, E. C. (2011). The context of trust repair efforts: Exploring the role of relationship dependence and outcome severity. Journal of Trust Research, 1, 139-157. doi: $10.1080 / 21515581.2017 .1293772$

Vancouver, J.B. (2008). Integrating self-regulation theories of work motivation into a dynamic process theory. Human Resource Management Review, 18, 1-18. doi: 10.1016/j.hrmr.2008.02.001

Vancouver, J.B., \& Day, D.V. (2005). Industrial and organisation research on self-regulation: from constructs to applications. Applied Psychology, 54, 155-185. doi: 10.1111/j.14640597.2005.00202.x

van der Werff, L., \& Buckley, F. (2017). Getting to know you: A longitudinal examination of trust cues and trust development during socialization. Journal of Management, 43, 742 770. doi: $10.1177 / 0149206314543475$

van Knippenberg, D. (2018). Reconsidering Affect-Based Trust: A new research agenda. In R. H. Searle, A.-M. I. Nienaber, \& S. B. Sitkin (Eds.), The Routledge companion to trust (pp. 3-13). Abingdon: Routledge.

Vansteenkiste, M., Simons, J., Lens, W., Sheldon, K. M., \& Deci, E. L. (2004). Motivating Learning, Performance, and Persistence: The Synergistic Effects of Intrinsic Goal 
Contents and Autonomy-Supportive Contexts. Journal of Personality and Social Psychology, 87, 246-260. doi: 10.1037/0022-3514.87.2.246

Webb, T. L., Miles, E., \& Sheeran, P. (2012). Dealing with feeling: A meta-analysis of the effectiveness of strategies derived from the process model of emotion regulation. Psychological Bulletin, 138, 775-808. doi: 10.1037/a0027600

Weber, J. M., \& Murnighan, J. K. (2008). Suckers or saviors? Consistent contributors in social dilemmas. Journal of Personality and Social Psychology, 95, 1340-1353. doi: $10.1037 / \mathrm{a} 0012454$

Weber, J.M., Malhotra, D., \& Murnighan, J.K. (2004). Normal acts of irrational trust: Motivated attributions and the trust development process. Research in Organizational Behavior, 26, 75-101. doi: 10.1016/S0191-3085(04)26003-8

Weinstein, N. (2014). Human motivation and interpersonal relationships. Springer Netherlands.

Williams, M. (2001). In whom we trust: Group membership as an affective context for trust development. Academy of Management Review, 26, 377-396. doi: 10.2307/259183

Williamson, O.E. (1993). Calculativeness, trust, and economic organization. Journal of Law and Economics, 36, 453-486.

Willis, J., \& Todorov, A. (2006). First impressions making up your mind after a 100-ms exposure to a face. Psychological Science, 17, 592-598. doi: 10.1111/j.14679280.2006.01750.x 
Figure 1. Trust Motivation Processes

Phase 1 - Trust Goal Setting (Pre-decisional)

Phase 2 - Trust Regulation (Post-decisional)
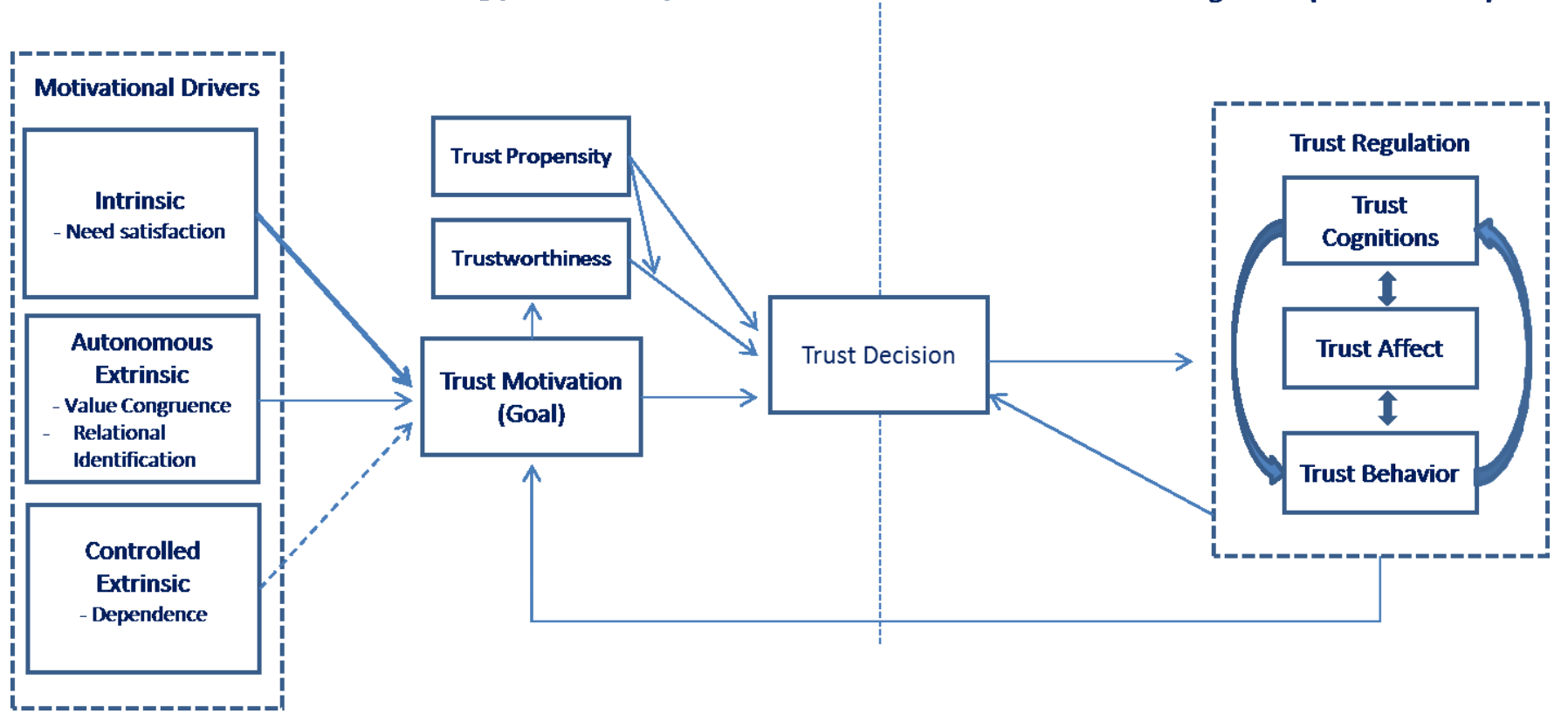

Note: The emphasis depicted in the arrows between the motivational drivers and trust motivation represents the differences in the robustness and persistence of goals driven by different trust motivation drivers in line with proposition 3. 
Figure 2. Trust Goal Setting and Regulation Processes

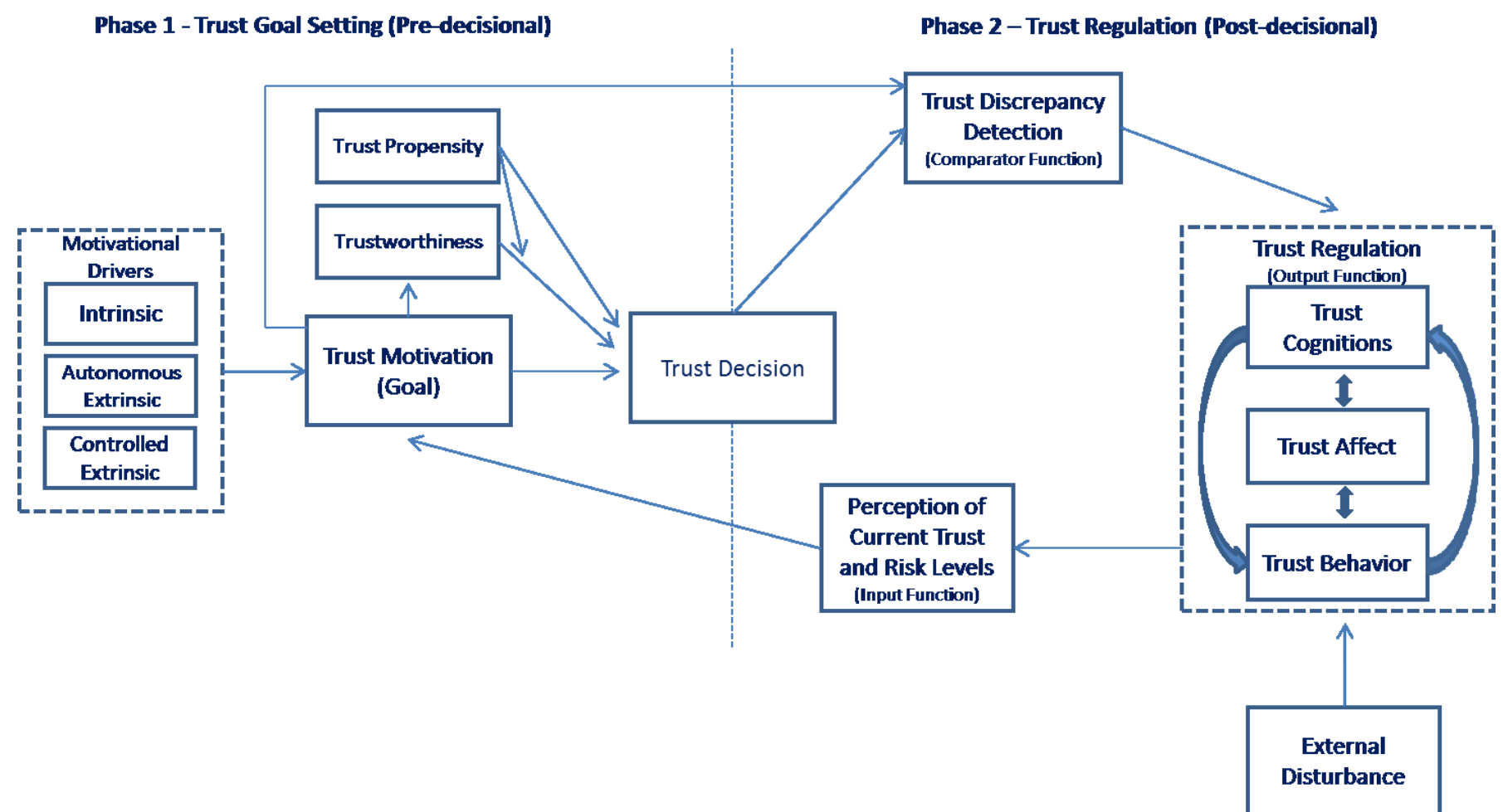

Note: The trust goal regulation process depicted above details the self-regulatory feedback loop driven by the detection of discrepancies between a trust decision (i.e. the current state) and the trust motivation goal (i.e. the referent standard) 